\title{
APLIKASI AUGMENTED REALITY UNTUK PEMBELAJARAN SALAT BAGI SISWA SEKOLAH DASAR
}

\author{
Yogiek Indra Kurniawan*1, Agung Fajar Surya Kusuma² \\ ${ }^{1}$ Informatika, Universitas Jenderal Soedirman, ${ }^{2}$ Informatika, Universitas Muhammadiyah Surakarta \\ Email: 1'yogiek@unsoed.ac.id, ${ }^{2}$ fajarkusuma46@gmail.com \\ *Penulis Korespondensi
}

(Naskah masuk: 04 Juli 2019, diterima untuk diterbitkan: 01 Februari 2021)

\begin{abstract}
Abstrak
Penggunaan media manual berbasis buku dan papan tulis memberikan beberapa permasalahan pada proses pembelajaran di sekolah. Berdasarkan survey yang telah dilakukan, Di Sekolah Dasar Insan Terpadu (SDIT) Muhammadiyah Al Kautsar yang menggunakan media manual untuk pembelajaran salat memiliki masalah mengenai tingkat minat dan tingkat pemahaman siswa yang kurang tinggi. Penelitian ini memiliki tujuan untuk mengembangkan media pembelajaran mengenai materi salat yang dapat membantu pihak sekolah agar mempunyai metode yang baru dan menarik dalam kegiatan pembelajaran di dalam kelas, terutama untuk materi Salat. Teknologi utama yang digunakan dalam aplikasi ini adalah Augmented Reality (AR). Dalam kasus ini, Augmented Reality $(A R)$ digunakan untuk memvisualisasikan materi Salat dalam bentuk 3D yang diproyeksikan pada tablet atau smartphone. Objek 3D juga diberi animasi agar terkesan realistis dan interaktif. Aplikasi ini membantu memvisualisasikan gerakan salat dalam bentuk 3D animasi. Aplikasi terdiri dari 2 menu, yaitu menu "Play AR" dan "Quiz". Hasil uji blackbox menunjukkan hasil valid yang berarti aplikasi sudah sesuai dengan yang diharapkan. Aplikasi dapat berjalan baik pada smartphone dengan sistem operasi minimal Kitkat. Rata-rata hasil uji validasi ahli sebesar $86 \%$ yang berada pada kategori "Sangat Baik". Hasil dari User Acceptance Test menunjukkan nilai rata-rata sebesar $89.88 \%$ dengan kategori "Sangat Baik". Penggunaan aplikasi AR pembelajaran salat dapat meningkatkan minat belajar siswa serta tingkat pemahaman siswa terhadap materi Salat yang ditunjukkan dengan peningkatan nilai sebelum dan sesudah menggunakan aplikasi.
\end{abstract}

Kata kunci : animasi, aplikasi, augmented reality, salat, 3D

\section{AUGMENTED REALITY APPLICATION FOR SALAT LEARNING FOR ELEMENTARY SCHOOL STUDENTS}

\begin{abstract}
The use of manuals media, such as books and whiteboard, provides several problems in the learning process in schools. Based on the survey that has been done At the Sekolah Dasar Insan Terpadu (SDIT) Muhammadiyah Al Kautsar, which uses manuals media for salat learning, there are problems with the level of interest and the level of student understanding that is not quite high. This research aims to develop a learning media about salat that is to help schools to have new and interesting methods in learning activities in the classroom, especially for Salat subject. The main technology used in this application is Augmented Reality (AR). In this case, Augmented Reality (AR) are used for visualizing the Salat material in $3 D$ object that will be projected on smartphone. $3 D$ object are animated to make it more realistic and interactive. Eventually, this application illustrate the motion of salat in $3 D$ animation object. The application consists of 2 menus, namely "Play AR" and "Quiz" menus. Blackbox test results show valid results, which means the application is as expected. The application can run well on smartphones with a minimum Kitkat operating system. The average expert validation test results are $86 \%$ in the "Very Good" category. The results of the User Acceptance Test show an average value of $89.88 \%$ with the "Very Good" category. The use of the Salat Learning AR application can improve student learning interest and the level of student understanding of the Salat subject which is indicated by an increase in the value before and after using the application.
\end{abstract}

Keywords: animation, application, augmented reality, salat, $3 D$ 


\section{PENDAHULUAN}

Sekolah Dasar (SD) adalah salah satu lembaga formal yang bergerak dalam bidang pendidikan. Dalam kegiatan belajar mengajar, guru akan berperan sebagai pembimbing yang menyampaikan materi kepada murid.

Sekolah Dasar Insan Terpadu (SDIT) Muhammadiyah Al Kautsar merupakan salah satu sekolah dasar bentukan Muhammadiyah yang terletak di Surakarta, Jawa Tengah. Pada SDIT ini, guru menyampaikan materi pelajaran sesuai dengan kurikulum yang telah ditentukan. Salah satu materi yang diajarkan oleh guru di SDIT Muhammadiyah Al Kautsar yaitu tata cara gerakan salat beserta dengan doa-doa salat yang diajarkan mulai dari kelas 1 dan diulang sampai di kelas 4 SD.

SDIT Muhammadiyah Al Kautsar mempergunakan buku dan papan tulis sebagai media pembelajaran utama. Guru mengajarkan murid dengan menulis di papan tulis di depan para siswa mengenai sebuah materi berdasarkan buku yang ada.

Berdasarkan survey yang telah dilakukan kepada 42 siswa di kelas 3 SDIT Muhammadiyah Al Kautsar, tingkat ketertarikan siswa terhadap materi salat yang diajarkan oleh guru hanya sebesar $42,8 \%$. Sedangkan tingkat pemahaman siswa terhadap materi hanya sebesar 40,4\% yang tergolong kurang tinggi.

Menurut Kurniawan dan Dwiyatmika (2017), diagnosa awal terhadap sebuah permasalahan pada anak merupakan langkah penting sebelum menyelesaikan permasalahan tersebut. Pada SDIT Muhammadiyah Al Kautsar, tingkat ketertarikan dan pemahaman materi yang rendah menjadi sebuah permasalahan yang harus diatasi oleh SDIT tersebut. Salah satu penyebab rendahnya tingkat ketertarikan dan pemahaman siswa sekolah dasar adalah karena para siswa masih sangat aktif dan susah untuk fokus dalam hal pelajaran sehingga materi tidak dapat diterima dengan efisien.

Salah satu solusi untuk meningkatkan minat ketertarikan serta pemahaman siswa adalah dengan menggunakan aplikasi berupa media pembelajaran. Aplikasi media pembelajaran telah diadopsi untuk dijadikan sebagai salah satu alat dalam penyampaian materi. Pada penelitian (Resnyansky et all, 2018) Pendekatan inovatif dalam pengajaran ilmu komputer dapat digunakan untuk memenuhi kebutuhan beragam target audiens, termasuk kelompok dengan latar belakang kekurangan kemampuan berpikir yang memadai.

Lingkungan dapat memberikan efek lebih dan meningkatkan potensi siswa belajar, khususnya lingkungan berbasis permainan dan aplikasi (Ak and Kutlu, 2017). Aplikasi media pembelajaran dalam bentuk Augmented Reality Edugame juga dapat menjadi metode alternatif yang membuat pembelajaran menjadi lebih mudah dan menyenangkan bagi siswa(Sudarmilah dkk, 2018).

Berdasarkan permasalahan yang ada, maka diperlukan aplikasi edukatif yang menarik untuk meningkatkan minat belajar para murid agar tidak cepat merasa bosan. Aplikasi ini juga dapat membantu murid belajar dirumah mengingat aplikasi mudah digunakan pada smartphone.

Proses pembelajaran yang baik yaitu adanya interaksi yang aktif antara guru dan murid. Kegiatan belajar juga dilakukan secara interaktif, menyenangkan, dan memfokuskan murid agar dapat aktif berpartisipasi dalam proses pembelajaran. Aplikasi berbasis Augmented Reality (AR) adalah salah satu sarana agar interaksi antara murid dan guru terbentuk. Peng Chen melakukan survey pada tahun 2016, bahwa AR semakin berkembang untuk diimplementasikan di dunia pendidikan. AR merupakan sebuah metode potensial yang dapat digunakan dalam dunia pendidikan saat ini. (Chen et all, 2016).

Augmented Reality (AR) merupakan teknologi perpaduan benda 3 dimensi atau 2 dimensi yang memproyeksikan benda tersebut di dunia nyata (Brata dan Brata, 2018). Augmented Reality (AR) juga didefinisikan sebagai teknologi penggabungan dunia maya dan dunia nyata serta memiliki sifat interaktif berdasarkan waktu nyata dan memiliki bentuk 3 dimensi.

Selain itu, menurut Ilmawan Mustaqim (2016), Augmented Reality (AR) didefinisikan sebagai teknologi penggabungan benda maya dalam 3 dimensi atau 2 dimensi pada lingkungan yang nyata dan dimunculkan atau diproyeksikan secara real time (Wu et all, 2013).

Menurut Ilmawan Mustaqim (2017), media pembelajaran dengan menggunakan AR dapat meningkatkan minat peserta didik serta proses pembelajaran. Hal ini disebabkan AR memiliki sisi hiburan untuk meningkatkan minat peserta dalam pembelajaran. Selain itu, AR juga melibatkan seluruh panca indera peserta didik sehingga membuat peserta menjadi lebih fokus. Hal ini dikarenakan AR mempunyai sifat serta fungsi yang mirip dengan media pembelajaran, yaitu memberikan informasi dari pengirim ke penerima serta memberikan penjelasan penyampaian informasi dan memberi rangsangan motivasi atau ketertarikan.

Ibanez \& Delgado-Kloos (2018) melakukan analisis pada 28 publikasi dari tahun 2010 hingga 2017 yang menunjukkan bahwa penggunaan teknologi augmented reality dapat digunakan untuk mendukung pembelajaran sains, teknologi, teknik dan matematika (STEM). Selain itu, menurut Barrow et all(2019), Teknologi Augmented Reality dapat dipergunakan di semua tingkatan pendidikan, mulai dari pendidikan dasar sampai tingkat pascasarjana.

Berdasarkan analisis diatas, pada penelitian ini dibuat sebuah aplikasi berupa media pembelajaran mengenai salat di SDIT Muhammadiyah Al Kautsar dalam bentuk Augmented Reality. Augmented Reality (AR) digunakan untuk memproyeksikan gerakan salat dalam bentuk tiga dimensi beserta animasinya. Dengan adanya aplikasi ini, tingkat minat dan 
pemahaman murid terhadap materi salat dapat meningkat.

\section{METODE PENELITIAN}

Metodologi yang digunakan dalam penelitian ini dapat ditunjukkan oleh gambar 1 .

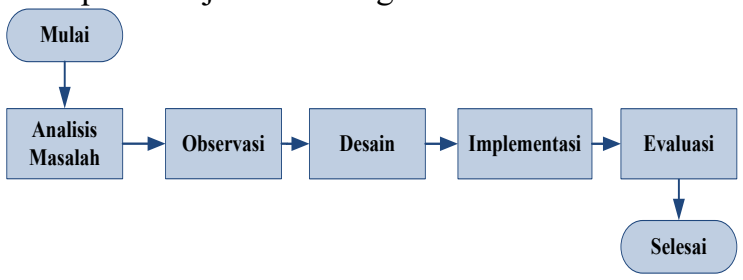

Gambar 1. Metodologi Penelitian

\subsection{Analisis Masalah}

Tahap analisis masalah digunakan untuk mencari permasalahan yang muncul pada saat penyampaian materi kepada murid. Permasalahan utama adalah mengenai tingkat ketertarikan atau minat siswa dan tingkat pemahaman siswa yang masih rendah terhadap materi salat yang diberikan. Berdasarkan permasalahan tersebut, dibutuhkan aplikasi edukatif dengan teknologi Augmented Reality $(A R)$ untuk meningkatkan fokus, minat belajar serta pemahaman murid sehingga materi dapat tersampaikan dengan lebih baik.

\subsection{Observasi}

Tahap observasi adalah tahapan untuk mengamati dan mencari semua data tentang gerakan salat yang benar agar tidak menyalahi aturan. Semua data yang didapat berasal dari Buku Praktis Ibadah dari SDIT Muhammadiyah Al Kautsar. Materi yang diambil disesuaikan dengan kurikulum di SDIT tersebut sehingga aplikasi ini dapat diimplementasikan secara berkala untuk pembelajaran salat.

\subsection{Desain}

Setelah memperoleh data, tahapan berikutnya adalah proses desain. Pada aplikasi pembelajaran salat ini, terdapat 2 modul, yaitu modul materi serta modul quiz. Pada modul materi diberikan teori berupa gerakan salat dalam bentuk 3D serta bacaan salat berupa audio. Pada modul quiz, diberikan beberapa pertanyaan terkait materi yang telah diberikan untuk mengukur tingkat pemahaman terhadap materi tersebut.

Desain aplikasi yang dilakukan adalah desain 3D modeling, rigging, dan animating yang menggunakan software Blender. Setelah objek 3D sudah jadi, proses selanjutnya yaitu menggabungkan objek 3D pada software Unity dan dikombinasikan dengan Augmented Reality (AR) menggunakan bantuan modul Vuforia.

\subsection{Implementasi}

Pada tahap ini, aplikasi sudah mulai dibuat menggunakan model yang sudah diprogram dalam Unity pada tahap desain. Bahasa pemrograman yang digunakan dalam aplikasi ini yaitu $C \#$ ( $C$ sharp) dan Javascript. Kemudian dilakukan compile ke dalam perangkat tablet atau smartphone sehingga siap digunakan.

Model yang dibangun untuk penggunaan AR dibuat dan dicetak dalam bentuk kartu bergambar yang disebut dengan marker. Marker digunakan untuk memicu tampilnya gambar 3D yang sesuai dengan gerakan salat. Menurut Idrus dan Yudherta (2016), marker bertujuan untuk mempermudah siswa dalam memahami materi dalam buku pelajaran, dimana gambar yang akan ditampilkan pada AR akan sesuai dengan marker tersebut.

Kartu tersebut berisi gambar gerakan-gerakan salat yang diajarkan di SDIT. Aplikasi yang telah diinstall pada smartphone hanya tinggal mengarahkan kamera ke kartu tersebut, kemudian aplikasi akan menampilkan gerakan salat beserta doa pada gerakan tersebut. Marker tersebut dicetak dan diberikan kepada setiap peserta didik agar bisa digunakan untuk pembelajaran, baik di sekolah maupun di rumah.

\subsection{Evaluasi}

Pengujian atau evaluasi perangkat lunak dapat dilakukan dengan 2 buah metode, yaitu pengujian fungsional dan pengujian non fungsional (Naik, 2008). Pengujian fungsional berupa pengujian terhadap fitur dan fungsionalitas dari perangkat lunak yang dibangun, dapat diuji menggunakan blackbox testing. Pengujian non fungsional berupa pengujian terhadap compability, usability ataupun kelayakan dari perangkat lunak.

Bagian Evaluasi dibagi menjadi dua tahap besar. Evaluasi pertama yaitu melakukan uji black box sebagai pengujian fungsional. Dalam pengujian ini dilakukan pengetesan aplikasi yang bertujuan untuk mengetahui apakah input dan output pada aplikasi sudah sesuai dengan yang diharapkan atau belum. Uji blackbox merupakan salah satu pengujian dari sisi developer atau pengembang aplikasi.

Tahap evaluasi kedua adalah pengujian non fungsional yang terbagi menjadi pengujian compability dari aplikasi, validasi ahli serta User Acceptance Test. Pada pengujian compability, dilakukan tes mengenai kompabilitas aplikasi terhadap berbagai macam sistem operasi Android yang ada pada smartphone.

Pada tahapan validasi ahli, aplikasi yang telah dibangun diuji oleh beberapa ahli di bidang media dan pendidikan dari sisi instruksional, isi konten serta kualitas aplikasi. Pengujian ini bertujuan untuk mengetahui apakah aplikasi sudah layak dari sisi media ataupun dari sisi materi.

Pengujian terakhir yaitu pengujian User Acceptance Test (UAT) atau Uji Penerimaan 
Pengguna. User Acceptance Test (UAT) merupakan sebuah pengujian yang diperuntukkan kepada pengguna aplikasi yang ditujukan untuk memperoleh sebuah dokumen yang dijadikan bukti bahwa perangkat lunak yang telah dibuat dapat diterima oleh pengguna. Pengujian ini dibuat dalam bentuk kuesioner dengan beberapa pertanyaan. Kuesioner tersebut disebarkan kepada pengguna, yaitu guru dan murid di SDIT Muhammadiyah Al Kautsar. Hasil dari kuesioner dapat dijadikan sebagai acuan keberhasilan dari aplikasi media pembelajaran yang telah dibangun.

Menurut Asyhari dan Silvia (2016), analisis angket pada game dilakukan dengan membandingkan jumlah skor perolehan dengan jumlah skor maksimal yang sudah ditetapkan dalam angket, seperti tertulis pada rumus (1).

$$
P=\frac{f}{N} \times 100 \%
$$

Keterangan:

$\mathrm{P}=$ Skor persentase yang dicari

$\mathrm{f}=$ Perolehan skor oleh validator

$\mathrm{N}=$ Skor maksimal

Penilaian dari hasil pengujian didasarkan pada indikator degradasi kategori yang dapat diperlihatkan oleh tabel 1.

\begin{tabular}{cc} 
Tabel 1. Indikator Kategori Penilaian \\
\hline Nilai P & Kategori \\
\hline $0 \%-20 \%$ & Sangat Buruk \\
$20.01 \%-40 \%$ & Buruk \\
$40.01 \%-60 \%$ & Cukup \\
$60.01 \%-80 \%$ & Baik \\
$80.01 \%-100 \%$ & Sangat Baik \\
\hline
\end{tabular}

\section{HASIL DAN PEMBAHASAN}

Pada bagian ini dijelaskan mengenai hasil implementasi dan evaluasi dari aplikasi augmented reality untuk pembelajaran salat yang telah dibuat.

\subsection{Implementasi Aplikasi}

Implementasi aplikasi merupakan tahap sebagai wujud realisasi dari rancangan aplikasi yang sudah dibuat untuk mengetahui hasil dari rancangan aplikasi.

Hasil dari penelitian ini adalah sebuah aplikasi edukasi untuk pembelajaran salat menggunakan teknologi Augmented Reality di SDIT Muhammadiyah Al Kautsar.

Aplikasi dibangun dengan menggabungkan objek 3D pada software Unity dan dikombinasikan dengan Augmented Reality (AR) menggunakan bantuan modul Vuforia. Bahasa pemrograman yang digunakan dalam aplikasi ini yaitu $C \#$ ( $C$ sharp) dan Javascript. Langkah terakhir yaitu melakukan compile ke dalam perangkat tablet atau smartphone untuk digunakan dalam pembelajaran.

\subsubsection{Halaman Utama}

Halaman utama dari aplikasi ini adalah menu awal. Di menu awal ini terdapat tombol play $A R$ dan Quiz. Tombol Play AR digunakan untuk masuk kedalam Scene AR. Tombol Quiz digunakan untuk masuk kedalam permainan kuis. Tombol exit berada di pojok kanan bawah untuk keluar dari aplikasi. Saat tombol exit ditekan, akan muncul notifikasi apakah pengguna yakin akan keluar dari aplikasi. Hal ini dilakukan untuk mengantisipasi jika tombol exit tidak sengaja ditekan oleh pengguna. Halaman utama dapat ditunjukkan pada Gambar 2.

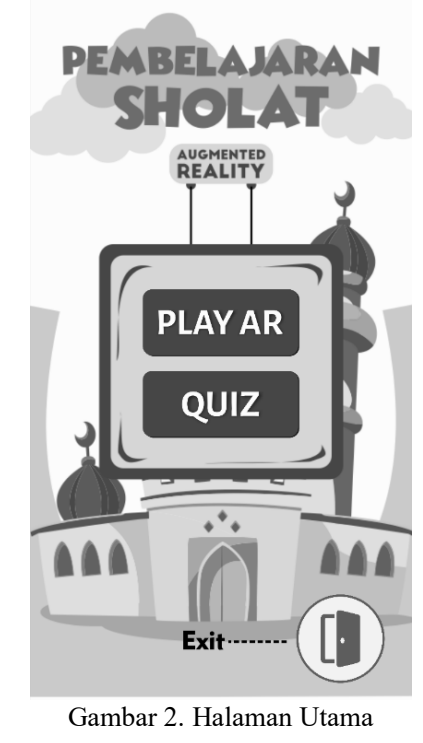

\subsubsection{Halaman Scene $A R$}

Halaman Scene $A R$ akan muncul setelah pengguna menekan tombol play $A R$. Di halaman ini pengguna langsung dapat menggunakan fitur $A R$ (Augmented Reality). Selain itu, terdapat tombol bantuan dengan simbol (?) disebelah kanan atas untuk memunculkan panel cara penggunaan aplikasi dan tombol reset untuk mengatur ulang animasi. Halaman scene $A R$ ditunjukkan pada Gambar 3.

Gerakan salat yang dimunculkan akan sesuai dengan gambar yang dituju oleh kamera pada smartphone. Sebagai contoh, pada gambar 4 ditunjukkan gerakan pada saat takbir. Pada saat smartphone mengarahkan kamera ke gambar "Takbir", maka akan muncul animasi berupa gerakan takbir, yaitu tangan menengadah ke atas sampai pada akhirnya menelungkupkan kedua tangan di depan perut. Gerakan tersebut disertai dengan bacaan atau doa pada saat takbir. Pada saat kamera diarahkan ke gambar "Al-Fatihah", animasi AR akan memperdengarkan surat Al-Fatihah disertai dengan doa dan bacaannya. Pada gambar 5, ditunjukkan gerakan dan bacaan pada saat ruku' serta sujud. Sedangkan pada gambar 6, diperlihatkan gerakan dan doa pada saat tasyahud dan salam. 

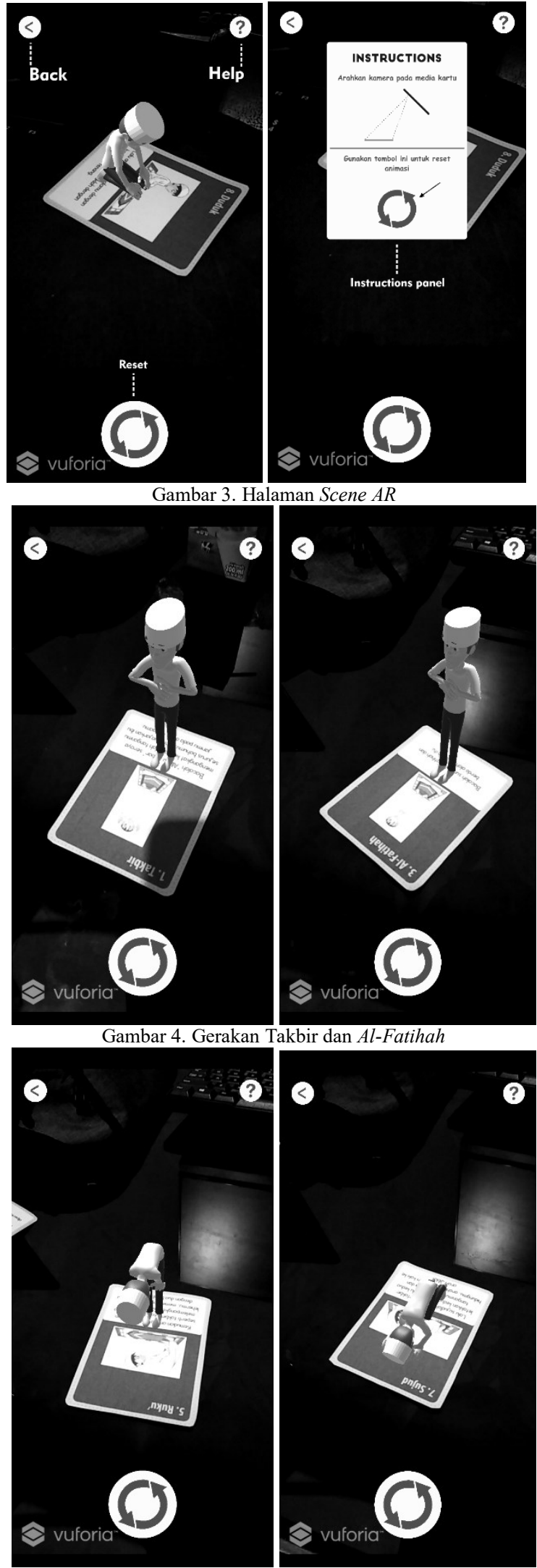

Gambar 5. Gerakan Ruku’ dan Sujud
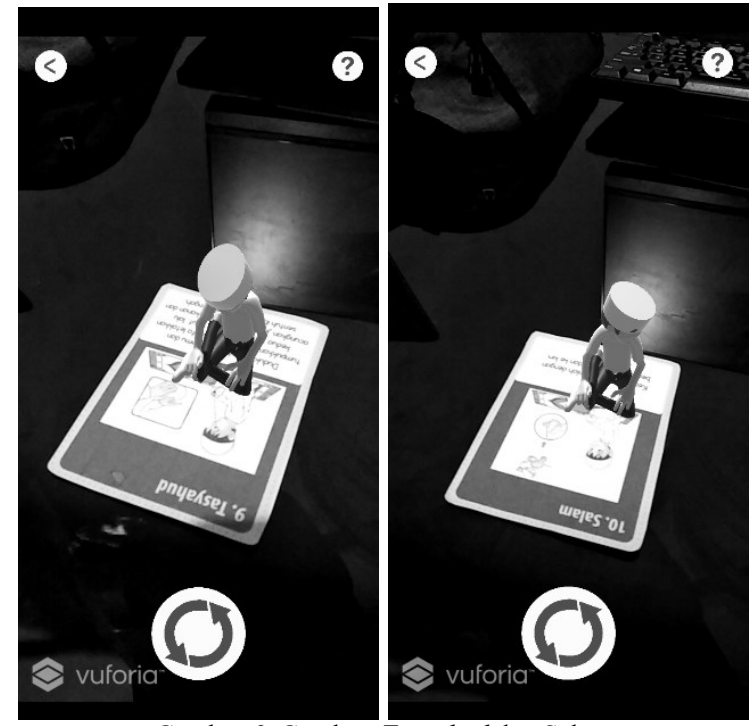

Gambar 6. Gerakan Tasyahud dan Salam

\subsubsection{Halaman Quiz}

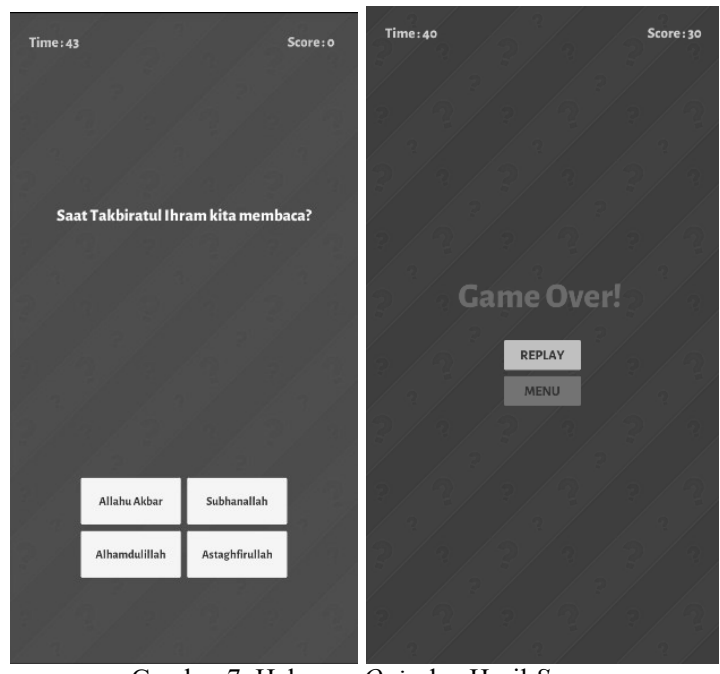

Gambar 7. Halaman Quiz dan Hasil Score

Halaman Quiz akan muncul setelah pengguna menekan tombol Quiz. Tampilan untuk halaman quiz dapat diperlihatkan oleh gambar 7. Pada halaman ini, pengguna diberi pertanyaan seputar materi. Terdapat total 25 soal pada database, sedangkan yang dimunculkan ke pengguna adalah 10 soal yang dipilihkan secara acak oleh aplikasi. Pilihan jawaban untuk pertanyaan tersebut berada di bawah soal. Setiap pertanyaan memiliki 4 pilihan jawaban dan terdapat 1 jawaban yang benar. Apabila pengguna memilih jawaban yang benar, maka Score akan bertambah 10. Dibagian pojok kiri atas terdapat Timer. Jika timer habis, kuis akan otomatis berakhir. Dan setelah berakhir, akan muncul panel Game Over. Pada halaman tersebut terdapat total score yang didapat. Terdapat juga dua tombol yang bertuliskan Replay dan Menu. Tombol Replay digunakan untuk memainkan kuis kembali, dan tombol Menu digunakan untuk kembali ke menu awal. 


\subsection{Evaluasi Aplikasi}

Evaluasi adalah tahapan dalam pengujian aplikasi, baik dari sisi pengembang aplikasi, sisi ahli media maupun dari sisi pengguna aplikasi.

\subsubsection{Uji Blackbox}

Pengujian blackbox bertujuan untuk menguji apakah aplikasi berjalan sesuai dengan yang diharapkan, yaitu dengan melakukan uji dengan beberapa test case(Al Irsyadi, Supriyadi et all, 2019). Pada setiap test case, diberikan input untuk melihat output dari aplikasi, apakah output yang dikeluarkan oleh aplikasi sudah sesuai dengan harapan pengembang aplikasi atau belum. Pengujian ini juga untuk mencari kesalahan yang ada dalam aplikasi dengan tujuan apabila menemukan kesalahan saat pengujian, dapat langsung dilakukan perbaikan. Hasil pengujian blackbox ditunjukkan pada Tabel 2 .

\begin{tabular}{|c|c|c|c|c|}
\hline No & $\begin{array}{l}\text { Menu / } \\
\text { Fitur }\end{array}$ & Test Case & $\begin{array}{c}\text { Hasil yang } \\
\text { Diharapkan }\end{array}$ & $\begin{array}{c}\text { Hasil } \\
\text { Pengujian }\end{array}$ \\
\hline 1 & Play AR & $\begin{array}{c}\text { Klik tombol } \\
\text { Main AR }\end{array}$ & $\begin{array}{c}\text { Masuk } \\
\text { kedalam } \\
\text { Scene } A R\end{array}$ & Valid \\
\hline 2 & Quiz & $\begin{array}{l}\text { Klik tombol } \\
\text { Quiz }\end{array}$ & $\begin{array}{c}\text { Masuk } \\
\text { kedalam } \\
\text { Scene Quiz }\end{array}$ & Valid \\
\hline 3 & Keluar & $\begin{array}{l}\text { Klik tombol } \\
\text { keluar di } \\
\text { menu utama. }\end{array}$ & $\begin{array}{l}\text { Muncul } \\
\text { kotak } \\
\text { konfirmasi } \\
\text { keluar atau } \\
\text { tidak. }\end{array}$ & Valid \\
\hline 4 & Keluar & $\begin{array}{c}\text { Memilih } \\
\text { keluar pada } \\
\text { kotak } \\
\text { konfirmasi. }\end{array}$ & $\begin{array}{l}\text { Keluar dari } \\
\text { aplikasi. }\end{array}$ & Valid \\
\hline 5 & $\begin{array}{l}\text { Muncul } \\
\text { objek } \\
\text { tiga } \\
\text { dimensi } \\
\text { beserta } \\
\text { audio }\end{array}$ & $\begin{array}{l}\text { Mengarahkan } \\
\text { kamera ke } \\
\text { kartu image } \\
\text { target. }\end{array}$ & $\begin{array}{c}\text { Muncul } \\
\text { objek tiga } \\
\text { dimensi dan } \\
\text { audio. Saat } \\
\text { image target } \\
\text { hilang, } \\
\text { objek dan } \\
\text { audio mati. }\end{array}$ & Valid \\
\hline 6 & Bantuan & $\begin{array}{c}\text { Klik tombol } \\
\text { bantuan saat } \\
\text { berada di } \\
\text { scene AR. }\end{array}$ & $\begin{array}{l}\text { Muncul } \\
\text { instruksi } \\
\text { cara } \\
\text { penggunaan } \\
\text { aplikasi. }\end{array}$ & Valid \\
\hline 7 & $\begin{array}{l}\text { Reset } \\
\text { Animasi }\end{array}$ & $\begin{array}{l}\text { Klik tombol } \\
\text { reset animasi }\end{array}$ & $\begin{array}{l}\text { Animasi di- } \\
\text { reset ulang. }\end{array}$ & Valid \\
\hline
\end{tabular}

Hasil uji blackbox menunjukkan bahwa pada semua menu yang telah dibuat sudah menunjukkan hasil valid atau seperti yang diharapkan oleh pengembang aplikasi.

\subsubsection{Uji Compability}

Uji compability digunakan untuk mengetahui requirement minimal yang dibutuhkan untuk menjalankan aplikasi. Pengujian terhadap beberapa smartphone dengan berbagai sistem operasi dapat diperlihatkan oleh tabel 3.

Berdasarkan hasil pengujian compability pada tabel 3, sistem operasi minimum pada smartphone yang diperlukan oleh aplikasi AR pembelajaran salat adalah sistem operasi Android OS 4.4.2 (Kitkat). Pada sistem operasi tersebut, semua fitur dan fungsionalitas aplikasi dapat berjalan dengan baik tanpa ada permasalahan, sedangkan pada sistem operasi di bawahnya, yaitu Android OS 4.2.2 (JellyBean), terdapat beberapa lag pada saat menjalankan animasi 3D.

Tabel 3. Hasil Uji Compability

\begin{tabular}{cc}
\hline Operating System & Hasil Aplikasi \\
\hline Android OS 7.0+ (Nougat) & Berjalan Baik \\
Android OS 6.0+ (Masrhmallow) & Berjalan Baik \\
Android OS 5.1.1 (Lollipop) & Berjalan Baik \\
Android OS 4.4.2 (Kitkat) & Berjalan Baik \\
Android OS 4.2.2 (JellyBean) & Animasi Lag \\
\hline
\end{tabular}

\subsubsection{Uji Validasi Ahli}

Pengujian ini dilakukan untuk mengetahui seberapa valid aplikasi AR ini dari sisi ahli. Pengujian dilakukan oleh beberapa ahli yang kompeten di bidang media dan pendidikan.

Uji validasi ahli media dilakukan untuk melakukan pengecekan dan validasi oleh beberapa ahli di bidang media dan pendidikan. Pada tahapan ini, aplikasi yang telah dibangun diuji oleh beberapa ahli media dari sisi instruksional, isi konten serta kualitas aplikasi. Pengujian menggunakan angket yang disusun untuk mengetahui validitas dari aplikasi. Terdapat 8 orang penguji dengan komposisi : 2 orang dosen yang mengajar multimedia di Informatika Universitas Muhammadiyah Surakarta, 1 orang dosen Informatika Universitas Jenderal Soedirman serta 5 orang guru Sekolah Dasar.

Hasil interpretasi ahli terhadap aplikasi dari sisi instruksional, isi konten dan kualitas aplikasi dengan menggunakan rumus (1) dapat ditunjukkan oleh gambar 8 .

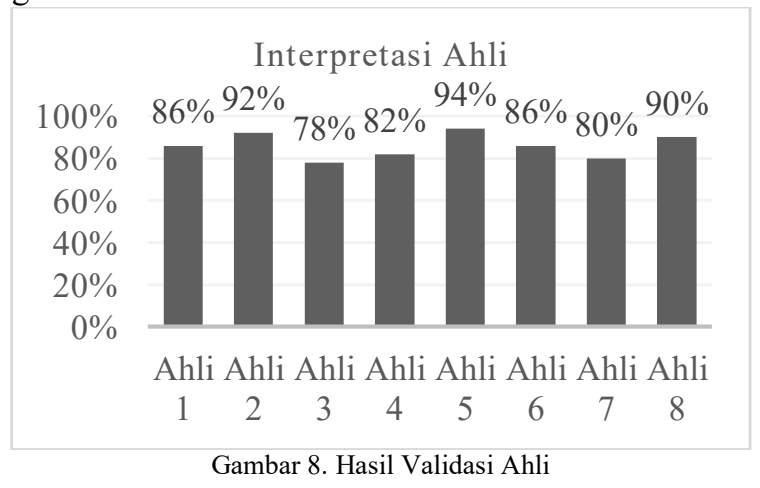

Rata-rata interpretasi validasi ahli yang telah dilakukan kepada 8 orang tersebut sebesar $86 \%$. Berdasarkan indikator kategori pada tabel 1, interpretasi ahli terhadap aplikasi AR yang telah dibangun berada pada kategori Sangat Baik.

\subsubsection{Uji Penerimaan Pengguna atau User Acceptance Test (UAT)}

Pengujian User Acceptance Test (UAT) berisi pertanyaan kepada pengguna aplikasi, yaitu murid di SDIT Muhammadiyah Al Kautsar. Pengujian UAT akan menghasilkan dokumen sebagai acuan apakah 
sebuah perangkat lunak media pembelajaran layak dan dapat diterima oleh pengguna (Al Irsyadi, Puspitassari, et all, 2019). Hasil pengujian UAT dari pengumpulan kuesioner yang sudah diberikan kepada 42 responden dapat ditunjukkan oleh tabel 4 . Tabel 4. Hasil Pertanyaan dan Jawaban Siswa

\begin{tabular}{|c|c|c|c|c|c|}
\hline No & Pertanyaan & SS & $\mathbf{S}$ & KS & TS \\
\hline P1 & $\begin{array}{l}\text { Apakah aplikasi ini } \\
\text { dapat digunakan sebagai } \\
\text { pengganti media buku } \\
\text { secara manual? }\end{array}$ & 20 & 20 & 1 & 1 \\
\hline P2 & $\begin{array}{l}\text { Apakah aplikasi ini } \\
\text { menarik untuk murid? }\end{array}$ & 30 & 11 & 1 & 0 \\
\hline P3 & $\begin{array}{l}\text { Apakah aplikasi ini } \\
\text { sesuai dengan materi } \\
\text { pembelajaran? }\end{array}$ & 24 & 16 & 2 & 0 \\
\hline P4 & $\begin{array}{l}\text { Apakah menu didalam } \\
\text { aplikasi } \\
\text { dipahami? }\end{array}$ & 28 & 12 & 0 & 2 \\
\hline P5 & $\begin{array}{l}\text { Apakah aplikasi ini } \\
\text { membantu } \\
\text { meningkatkan minat } \\
\text { belajar murid? }\end{array}$ & 28 & 13 & 1 & 0 \\
\hline P6 & $\begin{array}{l}\text { Apakah aplikasi ini } \\
\text { membuat } \\
\text { memahami } \\
\text { pembelajaran dan tata } \\
\text { cara salat? }\end{array}$ & 32 & 9 & 1 & 0 \\
\hline
\end{tabular}

\begin{tabular}{clc}
\multicolumn{3}{c}{ Tabel 5. Bobot Nilai Jawaban } \\
\hline No & \multicolumn{1}{c}{ Menu / Fitur } & $\begin{array}{c}\text { Hasil } \\
\text { Pengujian }\end{array}$ \\
\hline 1 & SS : Sangat : Mudah/Bagus/Sesuai/Jelas & 4 poin \\
2 & S : Mudah/Bagus/Sesuai/Jelas & 3 poin \\
3 & KS : Kurang : Mudah/Sesuai/Jelas & 2 poin \\
4 & TS : Tidak : Mudah/Bagus/Sesuai/Jelas & 1 poin \\
\hline
\end{tabular}

\begin{tabular}{cccc}
\multicolumn{4}{c}{ Tabel 6. Hasil Pengolahan Jawaban Responden } \\
\hline No & Nilai $\mathbf{~}$ & Nilai P & Indikator Kategori \\
\hline P1 & 143 & $85.12 \%$ & Sangat Baik \\
P2 & 155 & $92.26 \%$ & Sangat Baik \\
P3 & 148 & $88.01 \%$ & Sangat Baik \\
P4 & 150 & $89.28 \%$ & Sangat Baik \\
P5 & 153 & $91.07 \%$ & Sangat Baik \\
P6 & 157 & $93.45 \%$ & Sangat Baik \\
Rata-Rata & 151 & $89.88 \%$ & Sangat Baik \\
\hline
\end{tabular}

Hasil uji UAT dikonversi dengan panduan bobot nilai jawaban yang dapat ditunjukkan oleh tabel 5 .

Data yang didapat dari jawaban siswa diolah dengan cara mengalikan setiap jawaban pada tabel 4 dengan bobot yang ada pada tabel 5 .

Nilai maksimal $\mathrm{N}$ untuk kuesioner tersebut adalah sebesar 42 siswa $\mathrm{x} 4$ poin $=168$ poin. Berdasarkan rumus (1), hasil dari perhitungan dengan mengalikan setiap jawaban dengan bobot maka didapat hasil sebagaimana ditunjukkan tabel 6 .

Dari hasil penilaian kuesioner pada tabel 6, ratarata persentase nilai setiap pertanyaan mencapai angka $89.88 \%$ dengan kategori "Sangat Baik". Hal ini menunjukkan aplikasi AR untuk pembelajaran salat layak untuk digunakan dalam proses belajar mengajar.

Menurut Kurniawan (2018), untuk mengetahui metode terbaik dari beberapa pilihan, maka diberikan perbandingan diantara beberapa metode yang ada. Berdasarkan hasil kuesioner yang disebarkan sebelum menggunakan aplikasi serta setelah menggunakan aplikasi, didapatkan hasil perbandingan pembelajaran manual menggunakan buku dan papan tulis dibandingkan dengan pembelajaran menggunakan aplikasi AR. Hasil perbandingan tersebut dapat ditunjukkan oleh tabel 7 . Tabel 7. Perbandingan Pembelajaran Manual dengan aplikasi AR

\begin{tabular}{lcccc}
\hline & Aspek & & $\begin{array}{c}\text { Pembelajaran } \\
\text { Manual }\end{array}$ & $\begin{array}{c}\text { Pembelajaran } \\
\text { dengan } \\
\text { Aplikasi AR }\end{array}$ \\
\hline $\begin{array}{l}\text { Tingkat } \\
\text { siswa }\end{array}$ & minat & belajar & $42.8 \%$ & $91.07 \%$ \\
$\begin{array}{l}\text { Tingkat } \\
\text { Siswa }\end{array}$ & Pemahaman & $40.4 \%$ & $93.45 \%$ \\
\hline
\end{tabular}

Penilaian pada P5 dan P6 yang merupakan permasalahan utama dapat teratasi dengan aplikasi AR Pembelajaran Salat. Hal ini ditunjukkan dari peningkatan minat belajar siswa dari $42.8 \%$ menjadi $91.07 \%$ dan peningkatan pemahaman siswa terhadap materi Salat dari $40.4 \%$ menjadi $93.45 \%$.

\section{KESIMPULAN}

bahwa:

Berdasarkan hasil penelitian dapat disimpulkan

1. Aplikasi Augmented Reality pembelajaran salat terdiri dari 2 menu, yaitu menu "Play $A R$ " dan "Quiz".

2. Hasil uji blackbox menunjukkan hasil valid yang berarti aplikasi sudah sesuai dengan yang diharapkan.

3. Rata-rata hasil uji validasi ahli sebesar $86 \%$ yang berada pada kategori "Sangat Baik".

4. Hasil dari User Acceptance Test menunjukkan nilai rata-rata sebesar $89.88 \%$ dengan kategori "Sangat Baik".

5. Penggunaan aplikasi AR pembelajaran salat dapat meningkatkan minat belajar siswa dari $42.8 \%$ menjadi $91.07 \%$ serta meningkatkan pemahaman siswa terhadap materi Salat dari $40.4 \%$ menjadi $93.45 \%$.

6. Dari hasil pengujian, dapat disimpulkan bahwa aplikasi ini layak digunakan sebagai media alternatif dalam pembelajaran Salat di SDIT Muhammadiyah Al Kautsar.

Saran untuk penelitian selanjutnya adalah penelitian mengenai Technology Acceptance Model untuk penerapan teknologi AR seperti ini secara keseluruhan serta dikaitkan dengan aspek psikologi siswa. Selain itu, penelitian AR dengan perpaduan teknologi terkini seperti Google Glass juga dapat dicoba.

\section{DAFTAR PUSTAKA}

AL IRSYADI, F. Y., PRIAMBADHA, A. P. \& KURNIAWAN, Y. I. 2020. Game Edukasi Bahasa Arab Untuk Siswa Sekolah Dasar Kelas IV. Jurnal Manajemen Informatika (JAMIKA), 10(1), 55-66. doi : https://doi.org/10.34010/jamika.v10i1.2581 
AL IRSYADI, F. Y., PUSPITASSARI, D., \& KURNIAWAN, Y. I. 2019. ABAS (Ayo Belajar Sholat): Game Edukasi Pembelajaran Sholat Untuk Anak Tuna Rungu Wicara. Jurnal Manajemen Informatika, 9(1), 17-28. doi : https://doi.org/10.34010/jamika.v9i1.1537

AL IRSYADI, F. Y., SUPRIYADI, S. \& KURNIAWAN, Y. I. 2019. Interactive educational animal identification game for primary schoolchildren with intellectual disability. International Journal of Advanced Trends in Computer Science and Engineering, 8(6), 3058-3064. Doi : https://doi.org/10.30534/ijatcse/2019/64862 $\underline{019}$

AK, O., \& KUTLU, B. 2017. Comparing 2D and 3D game-based learning environments in terms of learning gains and student perceptions. British Journal of Educational Technology, 48 No. 1, 129-144. doi : 10.1111/bjet.12346

ASYHARI, A., \& SILVIA, H. 2016. Pengembangan Media Pembelajaran Berupa Buletin dalam Bentuk Buku Saku untuk Pembelajaran IPA Terpadu. Jurnal Ilmiah Pendidikan Fisika Al-Biruni, 5(1), 1-13.

BARROW, J., FORKER, C., SANDS, A., O'HARE, D., \& HURST, W. 2019, March. Augmented reality for enhancing life science education. In VISUAL 2019-The Fourth International Conference on Applications and Systems of Visual Paradigms.

BRATA, K. \& BRATA, A. 2018. Pengembangan Aplikasi Mobile Augmented Reality untuk Mendukung Pengenalan Koleksi Museum. Jurnal Teknologi Informasi dan Ilmu Komputer, 5(3), 347-352. doi : http://dx.doi.org/10.25126/jtiik.201853798

CHEN, P., LIU, X., CHENG, W., \& HUANG, R. 2017. A review of using Augmented Reality in Education from 2011 to 2016. In Innovations in smart learning (pp. 13-18). Springer, Singapore.

IBÁÑEZ, M. B., \& DELGADO-KLOOS, C. 2018. Augmented reality for STEM learning: A systematic review. Computers \& Education, 123, 109-123.

IDRUS, A. \& YUDHERTA, A. 2016. Pengembangan Augmented Reality Sebagai Media dalam Meningkatkan Pemahaman Teks Bacaan. JTP - Jurnal Teknologi Pendidikan, 18(3), 144-155.

https://doi.org/https://doi.org/10.21009/JTP 1803.3

KURNIAWAN, Y. I. 2018. Perbandingan Algoritma Naive Bayes dan C.45 dalam Klasifikasi Data Mining. Jurnal Teknologi Informasi dan Ilmu Komputer, 5(4), 455-464. doi : http://dx.doi.org/10.25126/jtiik.201854803

KURNIAWAN, Y. I., \& DWIYATMIKA, W. 2017. Aplikasi Diagnosa Retardasi Mental Pada Anak.

MUSTAQIM, I. 2016. Pemanfaatan Augmented Reality Sebagai Media Pembelajaran. Jurnal Pendidikan Teknologi dan Kejuruan, 13(2).

MUSTAQIM, I. 2017. Pengembangan Media Pembelajaran Berbasis Augmented reality. Jurnal Edukasi Elektro, 1(1).

NAIK, K. \& TRIPATHY, P. 2008. Software Testing and Quality Assurance Theory and Practice. Canada : Wiley

RESNYANSKY, D., İBILI, E., \& BILLINGHURST, M. (2018, December). The Potential of Augmented Reality for Computer Science Education. In 2018 IEEE International Conference on Teaching, Assessment, and Learning for Engineering (TALE)(pp. 350356). IEEE.

SUDARMILAH, E., SUPRIYONO, H., FADLILAH, U., AL IRSYADI, F. Y., \& FATMAWATI, A. 2018. Prototyping AR EduGame for children: learning Indonesian culture. In MATEC Web of Conferences(Vol. 197, p. 03012). EDP Sciences.

WU, H. K., LEE, S. W. Y., CHANG, H. Y., \& LIANG, J. C. 2013. Current status, opportunities and challenges of augmented reality in education. Computers \& education, 62, 41-49. 